\title{
Correlation of serum ferritin with glycemic control in type 2 diabetes mellitus patients at a tertiary health facility
}

\author{
A Praveen Naik ${ }^{1 *}$, Rajesh Reddy K² \\ ${ }^{1,2}$ Assistant Professor, Department of General Medicine, Kamineni Institute of Medical Sciences, Narketpally, Nalgonda, Telangana. INDIA. \\ Email: praveendr1986@gmail.com
}

Abstract Background: Diabetes Mellitus is a noncommunicable disease having predominant public health concern, affecting millions of people worldwide. Studies have shown that serum ferritin was proportional to serum glucose concentration, diastolic blood pressure, HDL cholesterol, and insulin resistance. However, role of ferritin as a marker of iron overload in pancreatic damage and peripheral insulin resistance or its role as an inflammatory marker is not clear. In present study we assessed level of serum ferritin in type 2 diabetes patients with good and poor glycemic control and also assessed the correlation between serum free iron concentrations with glycemic control. Material and Methods: This study was prospective, cross-sectional type, conducted between September 2019 to March 2020 in outpatient department of general medicine, of our hospital. This study comprises 100 patients with type 2 diabetes mellitus (treated with hypoglycemic drugs), as cases and 100 patients, age and sex matched apparently healthy adults as a control group. Results: After applying inclusion and exclusion criteria, total 200 patients (100 diabetic and 100 healthy) were enrolled in present study. Age and sex difference between two groups was statistically non-significant. Serum ferritin, BMI, fasting blood glucose (mg/dl) and glycated haemoglobin (HbA1C) values were significantly higher in diabetic group as compared to control group. Increase in serum ferritin levels was noted with increasing values of HbA1C. Correlation between serum ferritin and HbAlc was also assessed. The correlation between glycated haemoglobin and serum ferritin was done by Pearson correlation test and it showed a significantly positive correlation $(\mathrm{r}=0.507)$ with serum ferritin. Conclusion: In present study, we noted a positive correlation between serum ferritin levels and increased HbAlc reflecting poor glycemic control. This highlights the need for strict glycemic control in these subjects.

Key Words: Fasting blood glucose, HbA1c, Serum ferritin, Type 2 diabetes mellitus.

*Address for Correspondence:

Dr A Praveen Naik, Assistant Professor, Department of General Medicine, Kamineni Institute of Medical Sciences, Narketpally , Nalgonda, Telangana. INDIA.

Email: praveendr1986@gmail.com

Received Date: 30/11/2019 Revised Date: 15/01/2020 Accepted Date: 08/02/2020

DOI: https://doi.org/10.26611/10211521

This work is licensed under a Creative Commons Attribution-NonCommercial 4.0 International License. $(\boldsymbol{\infty})$ ) EY-NC

\begin{tabular}{|l|l|}
\hline \multicolumn{2}{|c|}{ Access this article online } \\
\hline Quick Response Code: & Website: \\
& www.medpulse.in \\
\hline
\end{tabular}

\section{INTRODUCTION}

Diabetes Mellitus is a noncommunicable disease having predominant public health concern, affecting millions of people worldwide. According to International Diabetes
Federation report, 415 million people worldwide have this disease and India harbours 69.1 million, the second highest number of diabetics in the world. Type 2 Diabetes mellitus (T2DM) is the most prevalent form of diabetes. It is expected that type 2 diabetes rise to $9.3 \%$ by year 2030 , particularly in Indian population, the reasons might include migration of human beings from rural to urban areas with change in dietary habits, and the shift to an increasingly sedentary lifestyle. ${ }^{2}$ Recent data show that about one third of the urban population in India's major cities has metabolic syndrome, major precursor of Type 2 Diabetes mellitus. ${ }^{3}$ Serum ferritin is an acute phase reactant and marker of iron stores in the body. Ferritin regulates blood iron levels by releasing iron if the blood has a low iron concentration and it can help to store excess iron if the blood and tissues have a high iron concentration. ${ }^{4}$ Studies 
have shown that serum ferritin was proportional to serum glucose concentration, diastolic blood pressure, HDL cholesterol, and insulin resistance. In fact, the higher the ferritin levels, the higher the incidence of type 2 diabetes mellitus. ${ }^{5,6}$ However, role of ferritin as a marker of iron overload in pancreatic damage and peripheral insulin resistance or its role as an inflammatory marker is not clear. ${ }^{7}$ Amongst the various markers of glycemic control, glycated haemoglobin has been established as the most reliable. Even moderately elevated iron can cause the above and hence the development of complications are linked to the accumulation of glycation. ${ }^{8}$ In present study we assessed level of serum ferritin in type 2 diabetes patients with good and poor glycemic control and also assessed the correlation between serum free iron concentrations with glycemic control.

\section{MATERIAL AND METHODS}

This study was prospective, cross-sectional type. It was conducted between September 2019 to March 2020 in outpatient Department of General Medicine, Kamineni Institute of Medical Sciences, Narketpally. Our institute is a tertiary care hospital. Study population was patients of type 2 diabetes mellites visiting outpatient department of our hospital.

This study comprises 100 patients with type 2 diabetes mellitus (treated with hypoglycemic drugs), as cases and 100 patients, age and sex matched apparently healthy adults as a control group.

Inclusion Criteria

Diabetic patients (type 2, treated with hypoglycemic drugs), age more than 30 years of both the gender. Diabetic patients met the criteria American Diabetes Association. ${ }^{9}$

Exclusion Criteria

Patients with anaemia (Haemoglobin levels less than $12 \mathrm{~g} / \mathrm{dl}$ in women and less than $13 \mathrm{~g} / \mathrm{dl}$ in males) or receiving treatment for anaemia in the past three months, Patients receiving iron supplements, pregnant women. Patients with history of blood donation in the last three months, Patients with diagnosed type 1 diabetes mellitus, Patients with hepatic disorders, renal disorders, malignancies, acute infections, fever, myocardial infarction, bleeding disorders or Patients with history of drug or alcohol abuse. Patients on medication with possible influence on serum ferritin levels. Patients who do not give consent to the study

All participants after their written informed consent underwent detailed physical and clinical examination. BMI was calculated using standard formula. Under all aseptic and antiseptic conditions $5 \mathrm{ml}$ of blood sample was collected from each subject (with overnight fasting) and divided into a sterile empty vial and an EDTA vial. EDTA vials are used for estimation of glycated hemoglobin and blood glucose. The rest of the sample was then allowed to stand for some time and then centrifuged for separation of serum. Blood glucose measurement by spectrophometric Glucose oxidase per oxidase (GOD-POD) method which is enzymatic, specific, accurate and rapid method of measurement of true blood glucose. Estimation of serum ferritin was done by using automated Chemiluminescence Immunoassay system (CLIA).

Statistical analysis Arithmetic mean and standard deviation were calculated to assess the levels of various parameters in both groups. Students ' $t$ ' test was used for comparison of quantitative variables. Co-relation between serum ferritin and $\mathrm{HbA} 1 \mathrm{c} \%$ in patients and co-relation between serum ferritin and fasting blood glucose levels was evaluated using Pearson Co-relation Co-efficient. All tests were considered statistically significant if the p-value was $<0.05$.

Ethical approval was taken from Institutional Ethical Committee.

\section{RESULTS}

After applying inclusion and exclusion criteria, total 200 patients (100 diabetic and 100 healthy) were enrolled in present study. Age and sex difference between two groups was statistically non-significant. On comparison of serum ferritin levels between cases and controls it was found that the mean serum ferritin of diabetic population was 138.88 $\pm 64.95 \mathrm{ng} / \mathrm{mL}$ and that of control group was $60.92 \pm 28.67$ $\mathrm{ng} / \mathrm{mL}$ ( $\mathrm{p}$ value $<0.05$ ). Serum ferritin of case group is therefore significantly higher than the control group. Similarly, BMI, fasting blood glucose $(\mathrm{mg} / \mathrm{dl})$ and glycated haemoglobin (HbA1C) values were significantly higher in diabetic group as compared to control group.

\begin{tabular}{cccc} 
Table 1: Comparison of means of the different anthropometric, clinical and biochemical characteristics \\
\cline { 2 - 4 } & Diabetic group & Control group & P value \\
\hline Parameters & $51.03 \pm 11.62$ & $50.91+12.23$ & $>0.05$ \\
Male / female & $46 / 54$ & $43 / 57$ & $>0.05$ \\
Serum ferritin $(\mathrm{ng} / \mathrm{mL})$ & $138.88 \pm 64.95$ & $60.92 \pm 28.67$ & $<0.01$ \\
BMI (Kg/m2) & $26.31 \pm 3.05$ & $23.81 \pm 2.69$ & $<0.01$ \\
Fasting blood glucose $(\mathrm{mg} / \mathrm{dL})$ & $161.28 \pm 48.51$ & $81.85 \pm 14.24$ & $<0.01$ \\
Glycated haemoglobin (HbA1C) (\%) & $8.92 \pm 2.21$ & $5.39 \pm 0.71$ & $<0.01$ \\
\hline
\end{tabular}

We compared serum ferritin values with $\mathrm{HbA1C}$ values in diabetic patients. Increase in serum ferritin levels was noted with increasing values of $\mathrm{HbA1C}$ as shown in table 2 . 
Table 2: Comparison of serum ferritin with $\mathrm{HbA} 1 \mathrm{C}$ in diabetic patients.

\begin{tabular}{cccc}
\hline HbA1C Range (\%) & No. & Mean \pm SD HbA1C\% & Serum Ferritin $(\mathrm{ng} / \mathrm{mL})$ \\
\hline $6-7.5$ & 32 & $6.89 \pm 0.62$ & $92.41 \pm 38.55$ \\
$7.51-9$ & 27 & $8.09 \pm 0.82$ & $119.24 \pm 21.83$ \\
$9.01-10.5$ & 23 & $9.93 \pm 0.45$ & $156.61 \pm 39.21$ \\
$>10.5$ & 18 & $11.89 \pm 1.13$ & $228.12 \pm 11.75$ \\
\hline
\end{tabular}

Correlation between serum ferritin and HbA1c was also assessed. The correlation between glycated haemoglobin and serum ferritin was done by Pearson correlation test and it showed a significantly positive correlation $(\mathrm{r}=0.507)$ with serum ferritin.

Table 3: Correlation between serum ferritin and HbA1c levels Group

\begin{tabular}{ccc}
\hline & Mean \pm SD & Pearson Correlation \\
\hline Serum Ferritin $(\mathrm{ng} / \mathrm{mL})$ & $138.88 \pm 64.95$ & .507 \\
Glycated haemoglobin $(\mathrm{HbA1C})$ & $8.92 \pm 2.21$ & \\
\hline
\end{tabular}

\section{DISCUSSION}

Elevated ferritin levels are usually due to multiple causes such as acute or chronic inflammation, chronic alcohol consumption, liver disease, renal failure, malignancy and overt thyroid dysfunction while ferritin levels are decreased in iron deficiency, excess menstruation, conditions that affect intestinal absorption of iron and any internal bleeding. ${ }^{10}$ Scientific studies has revealed unsuspecting influences between iron metabolism and type 2 diabetes. The relationship is bi-directional; iron affects glucose metabolism, and glucose metabolism impinges on several iron metabolic pathways. It is increasingly recognised that iron influences glucose metabolism, even in the absence of significant iron overload. ${ }^{11}$ Other mechanisms related to serum ferritin are, potent hydroxyl radicals from iron by Heber-Weiss and Fenton reactions impair mechanism of vasodilatation, disrupt endothelium, accelerate development of atherosclerosis, diabetic nephropathy, and other microvascular complications associated with type II diabetes within 7 years. ${ }^{12}$ Elevated iron stores may induce diabetes through a variety of mechanisms, including oxidative damage to pancreatic beta cells, impairment of hepatic insulin extraction by liver, and interference with insulin's ability to suppress hepatic glucose production. ${ }^{13}$ In present study levels of BMI, fasting blood glucose, $\mathrm{HbAlc}$ and serum ferritin were significantly higher in diabetic patients as compared to controls. Similar findings were noted by Chandrashekhar et al..$^{14}$ and Kundu et al.. ${ }^{15}$ A significant increase in serum ferritin levels was observed in diabetic patients with raised $\mathrm{HbA} 1 \mathrm{c}$ compared to well controlled ones, findings are consistent with the study of Chandrashekhar et al.. ${ }^{14}$ They also observed that serum ferritin was increased in type 2 diabetic patients as long as glycemic control was not achieved. Others have also studied and found that serum ferritin, a reflector of body iron stores, was significantly higher in diabetic patients when compared to controls and is significantly increased with the duration of diabetes and HbAlc values. ${ }^{16,17}$ In a 6.5-year follow-up in Finnish adults, they observed increased in serum ferritin over a 6.5 -year period was associated with development of MetS in both men and women. A lower increase in serum ferritin over the same timeframe are associated with resolution of hypertriglyceridemia in men and hyperglycaemia in women. A positive correlation between waist circumference and serum ferritin levels in both the genders was also observed. ${ }^{18}$ Pramiladevi et al. . noted a significant correlation in diabetics compared with individuals with normal blood sugar regarding increased serum ferritin, and hyperferritinemia may be one of the causes for development of insulin resistance before overt diabetes. ${ }^{19}$ Contrary to present study, Thilip Kumar G et al. reported that patients with type 2 diabetes had significantly higher serum ferritin level when compared to healthy controls but there is no correlation between serum ferritin with mean blood glucose and $\mathrm{HbAlc} .{ }^{20} \mathrm{~A}$ variety of limitations of present study, also need to be addressed. Small sample-size did not allow a multivariate approach for incorporating additional factors for modifying the levels of serum ferritin and $\mathrm{HbAlc}$. Routine screening for serum ferritin levels among diabetics can provide additional information. More clinical trials on research for serum ferritin levels in a larger population and thereby intervening iron metabolism as one of the possible modalities in treating diabetic individuals.

\section{CONCLUSION}

In present study, we noted a positive correlation between serum ferritin levels and increased $\mathrm{HbAlc}$ reflecting poor glycemic control. This highlights the need for strict glycemic control in these subjects. Further studies are needed to verify the importance of screening of hyperferritinemia in type 2 diabetic patients and to define cut-off level of serum ferritin for possible early detection and subsequent prevention or delaying of impaired glucose tolerance and diabetes in those participants. 


\section{REFERENCES}

1. International Diabetes Federation, Diabetes Atlas, 7th edition, 2015.

2. Ramachandran A, SnehalathaS C, Kapur A, Vijay V, Mohan V, et al.. (2001) High prevalence of diabetes and impaired glucose tolerance in India: National Urban Diabetes Survey. Diabetologia 44: 1094-1101

3. Enas EA, Deepa VM, Farooq S, Pazhoor S, Chennikkara $\mathrm{H}$. The metabolic syndrome and dyslipidemia among Asian Indians: a population with high rates of diabetes and premature coronary artery disease. J Cardiometabo Syndrome. 2007;2(4)267-75.

4. Jiang R, Manson JE, Meigs JB, Ma J, Rifai N, Hu FB. Body iron stores in relation to risk of type 2 diabetes in apparently healthy women. JAMA 2004;291:711-7.

5. Forouhi NG, Harding AH, Allison M, Sandhu MS, Welch A, Luben Re et al. . Elevated serum ferritin levels predict new-onset type 2 diabetes: results from the EPIC-Norfolk prospective study. Diabetologia 2007; 50: 949-56.

6. Wrede CE, Buettner R, Bollheimer LC, Scho lmeirch J, PalitzschK- D and Hellerbrand C. Association between serum ferritin and the insulin resistance syndrome in a representative population. Eur J Endocr 2006; 154: 33340.

7. Sharifi F and Sazandeh Sh. Serum ferritin in type2 diabetes mellitus and its relationship with $\mathrm{HbA1c}$. Acta Med Iranica 2004; 42(2): 142-45.

8. Nitin S. HbA1c and factors other than diabetes mellitus affecting it. Singapore Med J 2010;51(8):616-622.

9. American Diabetes Association (2012): Diagnosis of diabetes mellitus. Diabetes Care, 1(27): 57-59.

10. John W Adamson. 19th edition Harrison's principles of Internal Medicine "iron deficiency anaemia and other hypoproliferative anaemia" chapter 126 page 625-30.

11. Pankaj B, Puja B, Akshay R et al.. Is serum ferritin associated with type II diabetes mellitus: A clinical study in a representative Indian population. J Med Sci Res 2011; 2: $20-4$.

12. Jehn M, Clark JM, Guallar E. Serum ferritin and risk of metabolic syndrome in U.S. adults. Diabetes Care 2004;27:2422-8.

13. Vaitla P, Vani N. Association between elevated serum ferritin and $\mathrm{HbA1C}$ in type 2 diabetes mellitus. IOSR 2017; 12: 57-59.

14. Chandrashekhar HR, Shekar HS, KiranNagaraju, Chikkalingiah and Bhagavan BC (2014): Association of Serum Ferritin Levels with Glycemic Control in type-2 Diabetes Mellitus. Indian J. of Pharmacy Practice, 7 (1): 58-61.

15. Kundu AR, Mandal T, Bandyopadhyay U, Ghosh E, and Ray D (2013): Relation of iron stores to oxidative stress in type 2 diabetes. Nigerian Journal of Clinical Practice, 16(1):100-103.

16. Sumesh Raj, G. V. Rajan. Correlation between elevated serum ferritin and $\mathrm{HbAlc}$ in type 2 diabetes mellitus. International Journal of Research in Medical Sciences Raj S et al. Int J Res Med Sci. 2013; 1(1): 12-15

17. Sanjeev Kumar and Ashima Badyal, Serum ferritin levels in type 2 diabetes mellitus and its relationship with HbA1c, International Journal of Current Advanced Research Vol 7, Issue 4(A), pp 11371-11373, April 2018

18. Hämäläinen $P$, Saltevo J, Kautiainen $H$, Mäntyselkä $P$, Vanhala M. Serum ferritin levels and the development of metabolic syndrome and its components: a 6.5- year follow-up study. Diabetology and Metabolic Syndrome. 2014;6:114.

19. Pramiladevi R, Boke U, Kora S. Serum ferritin levels in type II diabetes mellitus. Sch J App Med Sci 2013; 1:472475.

20. Thilip Kumar G, Saravanan A, Ramachandran C and John Nitin Ashok. Mean blood glucose level and glycated haemoglobin level in patients of non-insulin dependent diabetes mellitus and its correlation with serum ferritin level. Int J Med Sci 2011; 4 (1 and 2): 13-17.

\section{Source of Support: None Declared Conflict of Interest: None Declared}

Policy for Articles with Open Access:

Authors who publish with MedPulse International Journal of Medicine, Print ISSN: 2550-7583, Online ISSN: 2636-4751 agree to the following terms: Authors retain copyright and grant the journal right of first publication with the work simultaneously licensed under a Creative Commons Attribution License that allows others to share the work with an acknowledgement of the work's authorship and initial publication in this journal.

Authors are permitted and encouraged to post links to their work online (e.g., in institutional repositories or on their website) prior to and during the submission process, as it can lead to productive exchanges, as well as earlier and greater citation of published work. 